\title{
Aproximación al Impuesto sobre el Patrimonio Neto
}

\author{
Por Javier Gutiérrez Pellejero
}

\section{NATURALEZA Y CARACTERISTICAS}

Este impuesto se implantó en España a raíz de la Ley 50/1977 de 14 de noviembre, de Medidas Urgentes y, desde un punto de vista estrictamente legal, con base en los artículos 1 y 2 de la citada ley, podemos calificarlo de excepcional y transitorio, directo y personal, que grava el patrimonio Neto de las Personas Físicas.

Excepcional, pues nació como consecuencia de unas Medidas Urgentes y, además, así se le califica en el art. 1 de la ley. Por otra parte, es excepcional en cuanto supone una gran novedad en el Sistema fiscal español, que nunca había contado con un impuesto de esta naturaleza.

Transitorio, pues está prevista su sustitución por el Impuesto sobre el Patrimonio Neto, un proyecto que fue publicado en el Boletín Oficial de las Cortes el 11 de enero de 1978, sin que, hasta la fecha, haya sido aprobado. Asimismo, se le da este carácter en la exposición de Motivos de la ley 50/77, justificando, por esta causa, la simplificación del gravamen y la sencillez de sus normas de valoración.

Directo, porque así lo afirma la ley en su art. primero y además impide su traslación jurídica, esto es, trasladar la carga del Impuesto a otras personas.

$Y$ por último, personal, ya que tiene en cuenta las condiciones personales del sujeto pasivo, además de estar configurado en torno a una persona.

Más ampliamente se le podría caracterizar como un tributo ordinario, excepcional, transitorio, directo, personal, general, principal, nominal, progresivo, base de datos del sistema, que incide sobre las personas físicas; subjetivo, simple, sensible a las coyunturas económicas y que recae sobre el Patrimonio Ne to de las Personas Físicas.

Ampliando estos caracteres podemos decir: 
El impuesto sobre el Patrimonio es un tributo ordinario, aunque la ley lo califica de extraordinario. Varias notas que en él concurren inducen a calificarlo así:

- Su periodicidad.

- El hecho de que el Impuesto haya sido concebido para pagarse con la Renta y no con el Patrimonio.

- Su vocación de permanencia. No olvidemos que, a pesar del largo tiempo transcurrido desde su entrada en vigor y pese a estar prevista su sustitución desde su nacimiento, ésta no se ha producido.

Excepcional, transitorio, directo y personal, por las características antes apuntadas.

General, puesto que el hecho imponible está formado por toda clase de bienes y derechos del sujeto pasivo.

Principal, pues nació sin conexión con el Impuesto sobre la Renta.

Nominal o Formal, por la pequefiez de los tipos, que hacen que, en realidad, este impuesto se pague con la renta.

Progresivo, puesto que la escala de tipos aplicable tiene este carácter.

- Base de datos, fundamentalmente, a causa de su relación con el IRPF y el Impuesto sobre Transmisiones.

Que recae sobre las personas fisicas, pues sólo tributan éstas y no las personas juridicas.

Subjetivo, porque tiene en cuenta para las deducciones de la base imponible, las circunstancias personales y familiares del sujeto pasivo.

Simple, prefiriendo para las valoraciones los criterios prácticos, buscando para cada elemento del Patrimonio el de más fácil cumplimiento, lo que origina que haya valores administrativos, históricos, medios y actuales.

Sensible a la coyuntura económica, sobre todo a la inflación, pues ha permitido por dos veces la actualización de valores administrativos, favoreciendo al contribuyente en el IRPF al disminuir la tributación en los incrementos de Patrimonio de las rentas nominales producidas por el alza de precios.

En cuanto a su ámbito espacial, se exige en todo el territorio nacional sin perjuicio de lo establecido en relación a los regímenes especiales por razón del territorio y de los tratados y convenios internacionales, según se establece en la O. M. de 14.01.78.

Espafia tiene suscritos convenios de doble imposición con Austria, Bélgica, Dinamarca, Finlandia, Francia, Noruega, Países Bajos, Reino Unido, Suecia, Suiza, Canadá y Rumanía.

\section{HECHO IMPONIBLE DEL IMPUESTO}

Está contemplado en el art. 2 de la Ley 50/77. "Constituye el hecho 
imponible del impuesto la propiedad de toda clase de bienes y la titularidad de derechos de contenido económico atribuibles al sujeto pasivo, conforme a los preceptos de esta ley en el momento del devengo."

"Se presumirá que también forman parte del Patrimonio los bienes y derechos de todas clases que hubieran pertenecido al sujeto pasivo durante el plazo transcurrido desde el primer o, en su caso, anterior devengo, salvo prueba de transmisión o reducción patrimonial."

Siguiendo a Breña, comentamos este artículo en tres aspectos principales: objeto imponible, hecho imponible y la presunción de pertenencia de bienes al sujeto pasivo establecida en el mismo.

Objeto imponible: El objeto imponible es el Patrimonio Neto, que podemos definir como el conjunto de bienes y derechos atribuibles al sujeto pasivo, conforme a la ley, con deducción de las deudas. La ley no admite al objeto imponible como categoría independiente del hecho imponible, aunque de forma indirecta alude a él en el art. primero y sexto.

En cambio, el Proyecto de Ley sobre el Patrimonio Neto si que definía expresamente el objeto imponible en su art. segundo: "Constituye el Patrimonio Neto del Sujeto Pasivo el conjunto de bienes y derechos de que sea titular con deducción de las cargas y gravámenes; que disminuyan su valor y de las deudas y obligaciones personales de que deba responder el sujeto pasivo."

\section{ASPECTOS DEL HECHO IMPONIBLE}

Consideraciones al artículo segundo de la ley.

1.-La ley lo define como la titularidad de bienes y derechos, desvinculándolo del objeto imponible que es el Patrimonio Neto. Asf, en la definición del hecho imponible no se tienen en cuenta las cargas o deudas que se relegan a elementos de cuantificación de la base imponible.

2.-Al mencionar la ley el contenido económico de los derechos, excluye todos aquellos derechos que carecen de él.

3.-La ley no hace una lista cerrada de los bienes y derechos sujetos al impuesto; no obstante, presenta una enumeración abierta en las normas de valoración de la base imponible.

Le ley no presenta supuestos de no-sujeción, lo que podría dar lugar a disquisiciones sobre si está o no sujeto el capital humano, entendido éste como el valor capitalizado de las ganancias que la persona espera obtener en el futuro como consecuencia de sus servicios personales. Atendiendo al tradicional concepto de Patrimonio, ha de entenderse que no está sujeto. El Proyecto de Ley declara expresamente la no sujeción del capital humano.

Por tener la misma configuración que el capital humano, los derechos 
de autor han de entenderse no sujetos, lo que ya considera el Proyecto de Ley cuando indica que no está sujeta a gravámenes "la titularidad de derechos que constituyan fuente de estrictas rentas de trabajo".

Con estas excepciones quedan sujetas al impuesto la titularidad de toda clase de bienes y de toda clase de derechos de significación económica, deduciendo de su valor las cargas y las deudas y obligaciones personales.

En cuanto a las exenciones, de forma poco técnica, se regulan en el art. sexto de la ley, que trata de las normas de valoración de la base imponible.

Se declaran exentos:

- Los inmuebles urbanos declarados expresa e individualmente monumentos histórico-artísticos.

\section{DEVENGO DEL IMPUESTO}

La Ley 50/77, en su art. 8, indica que el impuesto se devengará el último día de cada año natural. La O. M. de 14 de enero de 1978 es más explícita e indica que "el impuesto se devengará el 31 de diciembre de cada año y afectará al patrimonio de que en dicha fecha sean titulares los sujetos pasivos".

Estos preceptos nos permiten hacer las siguientes precisiones:

- Los bienes y derechos computables son aquellos de los que es titular el suje to pasivo a 31 de diciembre de cada año.

- Sólo deben existir declaraciones por las personas vivas en 31 de diciembre. En el año, cada heredero o legatario debe añadir a su patrimonio el que le corresponda por sucesión y, si desconoce la cuantía, debe indicar este hecho en la declaración.

- No se admiten, en general, fórmulas de promediación, salvo en los saldos de cuentas corrientes y libretas de ahorro.

\section{ELEMENTOS PERSONALES}

Sujeto Pasivo y Contribuyente.

La ley indica en su art. tercero que "serán sujetos pasivos las personas físicas...", por lo que no son sujetos pasivos las sociedades ni las entidades a que se refiere el art. 33 de la LGT. Se excluyen de gravamen el patrimonio de las sociedades, para evitar la doble imposición que se produciría al gravar el patrimonio de la sociedad y los títulos representativos de su capital en manos de los accionistas.

En este impuesto, y salvo algunas obligaciones formales que regula 
la ley en determinados supuestos, obligando a cumplirlas a persona distinta de la destinataria última del impuesto, el sujeto pasivo es también contribuyente.

Llama la atención el distinto tratamiento del elemento personal en este impuesto con referencia al Impuesto sobre la Renta de las Personas Fisicas, ya que en el primer caso es la persona física individual y en el segundo la unidad familiar.

\section{MODALIDADES DE EXACCION}

El impuesto puede exigirse por obligación personal y por obligación real.

Obligación personal: En esta modalidad se grava la totalidad del Patrimonio del suje to pasivo, con independencia del país en que esté situado ( $\mathrm{Pa}$ trimonio Mundial).

Son sujetos pasivos por obligación personal:

a) Los que tengan su residencia habitual en territorio español.

b) Los representantes y funcionarios del Estado español en el extranjero que indica el art. 5.0 de la O. M. de 14 de enero de 1978.

c) Los sujetos no residentes, sujetos por obligación real, que tengan la nacionalidad española en el caso de que ejerciten el derecho de opción el art. $4.0^{\circ}$ de la orden citada anteriormente.

Los sujetos pasivos a los que afecta la obligación real de contribuir son:

a) Las personas físicas, no residentes, que sean titulares de bienes en territorio español o de derechos que en él pudiera ejercitarse.

A este respecto, se ha criticado por la doctrina el hecho de que no se grave el patrimonio en España de las sociedades extranjeras, pues en este caso, ya no se da el clásico argumento de la doble imposición.

b) Los representantes de los Estados extranjeros, acreditados en España, a condición de reciprocidad.

En el caso de obligación real de contribuir los bienes poseidos en España y los derechos que aquí puedan ejercitarse.

Cuando la obligación adquiere este carácter, el tributo toma carácter real, por lo que se deben tener en cuenta estas consideraciones:

1.-Solamente son deducibles las cargas y gravámenes que afecten a los bienes $y$ derechos sitos en territorio español y las deudas por capitales invertidos en esos bienes.

2.--No se aplican ni los mínimos de exención, ni las deducciones en la 
base imponible que previene la ley.

3.-Tampoco procede la acumulación prevista en el art. 4 de la ley de los bienes del matrimonio e hijos menores no emancipados.

4.-Existe obligación de declarar siempre, sea cual sea el valor de los bienes y derechos, lo que está en consonancia con la no-aplicación de los mínimos de exención. jero.

5.-No puede aplicarse la reducción por doble imposición en el extran-

6.-Los sujetos pasivos en los que incida la obligación real de contribuir vienen obligados a designar un representante con domicilio en territorio español, a efectos de sus relaciones con la Hacienda Pública (art. 46 de la LGT).

\section{RESIDENCIA HABITUAL}

La ley, en su art. 3, considera sujetos al impuesto "por obligación personal a los que tengan su domicilio o residencia habitual en España", lo que nos obliga a profundizar en los conceptos de domicilio o residencia habitual, a efectos de la aplicación del impuesto.

Para atender. el concepto de domicilio debemos atender a la LGT, que en su art. 45 dice: "El domicilio, a los efectos tributarios será:

a) Para las personas naturales, el de su residencia habitual, lo que nos indica la coincidencia del criterio de domicilio con el de la residencia habitual. A los efectos de determinación de la residencia habitual la Ley 50/77 se remite al ya hace tiempo desaparecido impuesto general sobre la Renta de las Personas Físicas, en cuyo art. 8 se indicaba: "Se entenderá por residencia habitual la permanencia por más de seis meses, durante el año natural, en territorio español. Para computar el período de residencia no se descontarán las ausencias cuando por las circunstancias en que se realicen deba introducir la voluntad de los interesados de no ausentarse definitivamente."

Es destacable la no conexión en este aspecto con el IRPF que ofrece una mejora técnica en el tratamiento de la residencia habitual, lo que aparece obviado en el Proyecto de Ley sobre el Impuesto sobre el Patrimonio Neto.

\section{ATRIBUCION E IMPUTACION DE PATRIMONIOS}

- Normas de atribución: El impuesto no grava la unidad familiar, pero establece unas normas de atribución de patrimonio en relación con la socie- 
dad conyugal, acumulando los bienes y derechos de determinados miembros de la unidad familiar.

La doctrina distingue tres supuestos:

- Acumulación absoluta: Se refiere al caso del matrimonio en régimen de sociedad legal de gananciales, viene recogido en el apartado 2 del art. 4 de la ley: "En caso de matrimonio en régimen económico de sociedad legal de gananciales o de comunidad de bienes se acumulan en la persona que tenga su administración, los bienes y derechos pertenecientes a los cónyuges y a la sociedad conyugal, así como los pertenecientes a los hijos menores no emancipados".

- Acumulación relativa: Se relaciona con matrimonio en régimen de separación de bienes no judicial.

En este caso se acumulan los bienes y derechos pertenecientes a ambos cónyuges y a los hijos menores no emancipados en la persona del marido, y si éste estuviera incapacitado, en la de la mujer, sin perjuicio del prorrateo de la exacción, según el patrimonio de cada cónyuge que lo efectuará en sujeto pasivo.

En este caso, el sujeto pasivo será el marido o la mujer, y contribuyente cada cónyuge por su parte de cuota correspondiente.

- Tributación independiente: Se usa en el supuesto de separación legal de bienes o divorcio. En este caso cada cónyuge hace declaración independiente, incluyendo sus bienes y los de los hijos que se encuentran bajo su patria potestad, siendo cada cónyuge sujeto pasivo del impuesto por separado.

Es de destacar que la normativa del impuesto en este campo ha sido superada por las leyes civiles, que han establecido tres regímenes económicos del matrimonio: régimen de gananciales, régimen de separación de bienes y régimen de participación, que es una auténtica novedad y que funciona como uno de separación de bienes durante su vigencia y como uno de gananciales a su extinción. Es obvio que en el caso de este Impuesto este régimen ha de hacerse como el de separación de bienes.

\section{NORMAS DE IMPUTACION}

Dado que la ley sólo considera sujetos pasivos a las personas físicas, no lo son las Entidades del art. 33 de la L.G.T., y la ley del Impuesto atribuye el Patrimonio de éstas a los componentes de tales entidades, según las normas aplicables a cada caso y, si éstas no constaran en forma fehaciente a la administración, por partes iguales.

Recordemos que el art. 33 de la L.G.T. indica: "Tendrán la consideración de sujetos pasivos, en las leyes tributarias en que así se establezca, las herencias yacentes, comunidades de bienes y demás entidades, que, carentes 
de personalidad jurídica, constituyan una unidad económica o patrimonio separado susceptible de imposición."

Es preciso abordar en este apartado determinadas reglas especiales de imputación de patrimonios:

- En el caso de un bien adquirido con precio aplazado habra que distinguir dos casos:

a) que exista cláusula de reserva de dominio.

Cuando concurre esta circunstancia, el bien se imputa al vendedor, que considera las cantidades que ha recibido del comprador, como deudas.

En cuanto al comprador, considera como activo las cantidades entregadas.

b) Que no exista cláusula de reserva de dominio.

En este caso el comprador incluye en su activo el valor total del bien y deduce en el apartado de deudas, la cantidad aplazada.

$\mathrm{El}$ vendedor incluye en su activo las cantidades recibidas y el derecho de crédito contra el comprador.

En el caso de existencia de cuentas corrientes, libretas de ahorro o similares de titularidad múltiple, su saldo se prorratea entre los cotitulares a partes iguales, salvo que a la administración le conste fehacientemente que han establecido diferente proporción.

Los certificados de depósito o documentos equivalentes se imputarán a la persona cuyo nombre figure en el Banco emisor, salvo prueba de que existe otro titular en el momento de devengo del impuesto.

La ley presume que forman parte del patrimonio del sujeto pasivo los bienes y derechos que hubieran pertenecido al mismo durante el tiempo transcurrido desde el anterior devengo, salvo prueba en contrario.

\section{DETERMINACION DE LA BASE IMPONIBLE}

A estos efectos el art. 5 de la Ley indica: "Constituirá la base imponible del impuesto la diferencia entre el valor de la totalidad de bienes y derechos atribuibles al sujeto pasivo de acuerdo con las normas anteriores, y el importe de las deudas acreditadas por documento público o por documento privado, que reúna los requisitos del art. 1.127 del Código civil, o de otro modo justifique la existencia de aquélla."

Además, la Orden Ministerial de 14 de enero de 1978, desarrollo de esta ley en lo que se refiere al Impuesto Extraordinario sobre el Patrimonio, dice en su art. 10:

"1.-La base imponible estará constituida por el valor del patrimonio neto del sujeto pasivo.

2.-El patrimonio neto se ${ }^{-}$determinará por diferencia entre: 
a) El valor real de los bienes y derechos que sean atribuibles al sujeto pasivo, $y$

b) Las cargas y gravámenes de naturaleza real, cuando disminuyan el valor de los respectivos bienes o derechos y las deudas u obligaciones de carácter personal."

Vemos que la Orden Ministerial añade calificativos a la ley. Donde ésta habla del valor de bienes y derechos, aquélla indica "el valor de bienes y derechos". Donde la ley habla de deudas, la O.M. habla de deudas u obligaciones de carácter personal $\mathrm{y}$ añade una referencia a las cargas y gravámenes de naturaleza real.

Definida la base imponible como la diferencia entre el valor de los bienes y derechos y las cargas y deudas, es obvio que para especificarla será necesario un proceso de cuantificación del valor, tanto de los bienes y derechos como de las cargas y deudas, proceso que precisará de unas normas detalladas, encuadradas por unas características generales y comunes a todo él.

Estas características son:

1.-No existe un único criterio de valoración, sino muchos. Como inconveniente se puede apuntar el que no todos los bienes soportan la misma carga tributaria.

2.-Tasación legal de los bienes. Ni la administración ni el sujeto pasivo tienen libertad de valoración, debiéndose ajustar a los métodos que indica la ley.

3.-Subsidiariedad del criterio del valor del mercado. Pese a que la OM. de 14 de enero de 1978 habla de "el valor real...", sólo se aplicará éste en el caso de no existencia de normas de valoración legales para cada caso específico.

Es de notar que las valoraciones legales suelen ser muy inferiores a los valores de mercado, dándose el caso de que un bien sea valorado por menos valor que las deudas contraidas para adquirirlo, sin que en la ley haya ningún mecanismo que pueda evitarlo.

4.-Criterios de valoración propios. Los criterios de valoración de este impuesto son distintos de los que tienen otros tributos. Sin embargo, hay mecanismos de relación intentando superar el problema causado por la variedad de criterios valorativos.

Los mecanismos de relación con los distintos impuestos son:

- Con el Impuesto sobre la Renta de las Personas Físicas: Influyen en cuanto al cálculo de los incrementos y disminuciones de patrimonio por cuanto éstos se determinan, con carácter general, por la diferencia entre valor de enajenación y de adquisición del bien, y la ley del I.R P.F. consideró como valor de adquisición el que figurase en la declaración del Impuesto Extraordinario sobre el Patrimonio, posterior a la entrada en vigor de la ley. Orurrirá que el valor real será muy superior al valor declarado en Patrimonio, lo que provocará una plusvalía inflacionista. Con el ánimo 
de corregir este inconveniente se permitió la actualización de valores en el Impuesto Extraordinario sobre el Patrimonio del año 1978 (declaración de 1979), con estos requisitos:

1.-Que fueran bienes adquiridos con anterioridad al 11 de septiembre de 1983.

2.-Que tuviesen un valor real superior al de compra.

3.-Que no se declarara un valor superior al de mercado.

4.-Los valores declarados han de mantenerse en posteriores declaraciones, a menos que se pruebe que la minoración obedece a la aplicación del mismo criterio adoptado en su día.

Respecto a esta condición, debemos entender que, dada la subjetividad del criterio aplicado, esta misma opinión personal del sujeto pasivo debería bastar para minorar el valor ya actualizado.

Estos valores actualizados carecen de cualquier influencia en las contribuciones Urbana y Rústica y Pecuaria, que tienen normas especfficas de valoración.

En cuanto a los que no tenfan obligaciones de declarar por el Impuesto sobre el Patrimonio en 1978, pudieron consignar el valor actualizado de sus bienes en la declaración del I.R.P.F. correspondiente a dicho año, y si no lo hicieron, se tomará como valor de esos bienes el que resulte de aplicar las normas de valoración del Impuesto sobre el Patrimonio, siempre que resultase un valor mayor que el de adquisición.

En el caso de personas que no estuvieron obligadas a declarar por ninguno de los dos Impuestos en 1979 y 1980, y para las transmisiones efectuadas durante 1980 y 1981 , el valor de los bienes será el de mercado a 31 de diciembre de 1978.

Otra acción del valor fijado en el Impuesto sobre el Patrimonio sobre el el I.R.P.F., a efectos del cómputo de un incremento o disminución patrimonial, se produce en el caso de aportación no dineraria, en que se tomará como valor de enajenación el mayor de estos tres:

1.-Valor nominal de la aportación.

2.-El valor de cotización en Bolsa de los títulos recibidos; y

3.-El valor obtenido según las normas del Impuesto Extraordinario sobre las personas físicas.

Otra influencia es en la renta imputada a la vivienda propia.

Se considera renta el 3 por 100 del valor fijado en el Impuesto sobre el Patrimonio, en la vivienda propia o utilizada a causa del cargo.

Por último, a efectos del cálculo de las amortizaciones en el I.R P.F., podría hacerse éste sobre el valor con que figuren los activos fijos materiales en la declaración del Impuesto sobre el Patrimonio de 1978. Si se hubiesen actualizado los valores, las amortizaciones podrán calcularse sobre el valor actualizado.

El Reglamento del I.R.P.F. en su art. 52, K, indica: "Las cantidades 
destinadas a la amortización de bienes, ...

Cuando se trate de inmuebles no afectos a actividades empresariales..., el 1,5 por 100 , sin incluir el valor de los terrenos.

Este porcentaje se aplicará sobre los siguientes valores:

1. - Si el sujeto pasivo está obligado a presentar declaración del Impuesto sobre el Patrimonio, sobre el valor que conste o debería constar en la declaración de dicho Impuesto correspondiente al perfodo impositivo en que deba estimarse la amortización como gasto deducible."

- Con el Impuesto sobre Sociedades:

Hay en este impuesto, una norma similar a la existente en el I.R.P.F., en relación con los incrementos y disminuciones de Patrimonio, en caso de aportaciones no dinerarias a Sociedades, computándose el valor de enajenación como el mayor de los tres siguientes:

- Valor de los bienes aportados en Impuesto

1) Extraordinario sobre el Patrimonio.

2) Valor nominal de la aportación.

3) Valor de cotización en Bolsa de los títulos recibidos.

- Con el Impuesto sobre transmisiones Patrimoniales y actos jurfdicos documentados. Neto.

Existe una relación estrecha entre este impuesto y el del Patrimonio

Tanto en el texto refundido de la ley como en el Reglamento del Impuesto sobre Transmisiones se indica que la base imponible será el valor real del bien determinado con arreglo a las normas de valoración del Impuesto sobre el Patrimonio, lo que puede plantear la duda de si la administración puede o no modificar estos valores mediante la actividad de comprobación.

La Dirección General de lo contencioso del Estado, en una disposición interpretativa, indica que la comprobación de valores "se concibe como una facultad del liquidador para el caso de que el valor declarado por los interesados o el resultado de la aplicación de las normas del Impuesto sobre el Patrimonio no refleje el valor real de los bienes y derechos transmitidos, de la operación societaria o del acto jurídico documentado".

No obstante lo anterior, si el sujeto pasivo se hubiere ajustado en su declaración a las normas de valoración del Impuesto sobre el Patrimonio no procederá la aplicación de sanción.

Además, el valor resultante de la comprobación en el Impuesto sobre Transmisiones y Patrimoniales y Actos Jurf́dicos documentados será el que habrá que tomar en el Impuesto sobre el Patrimonio, en el año en que tenga lugar la comprobación y en los siguientes, en caso de bienes adquiridos después del 1 de julio de 1980 , y que hubieran tributado por Impuesto de Transmisiones Patrimoniales y Actos Jurfdicos Documentados. 


\section{NORMAS ESPECIFICAS DE VALORACION}

a) Bienes de naturaleza urbana: La ley indica en su art. 6:

a) "Los bienes de naturaleza urbana se computarán por su valor catastral, multiplicado por los coeficientes que a continuación se relacionan, según el año de la implantación:

\begin{tabular}{cl}
\hline ANOS & COEFICIENTE \\
\hline $1968-1969$ & 2 \\
$1970-1972$ & 1,8 \\
1973 & 1,55 \\
1974 & 1,35 \\
1975 & 1,23 \\
1976 & 1,08 \\
1977 & 1 \\
\hline
\end{tabular}

No obstante, cuando la renta catastral sea inferior al $4 \%$ del valor catastral, los bienes se computarán capitalizando al $4 \%$ la renta catastral correspondiente al período en que se devenge el impuesto, sin que proceda la aplicación de los coeficientes a que se refiere el apartado anterior.

Cuando en el momento del devengo del impuesto existan en el Patrimonio del contribuyente bienes de naturaleza urbana pendientes de valoración catastral, se estimará como valor de los mismos el de adquisición, sin perjuicio de la posterior adquisición y actualización de valor, si procediese.

La O. M. de 17 de enero de 1983 añade a lo anterior la norma siguiente referida a bienes urbanos en construcción: art. 11.1 a) párrafo sexto: "Cuando los bienes de naturaleza urbana estén en fase de construcción, se estimará como valor patrimonial las cantidades que efectivamente se hubieren invertido hasta la fecha del devengo del impuesto, además del correspondiente valor patrimonial del solar, $y$ en caso de propiedad horizontal, la parte proporcional en el valor del solar según el porcentaje fijado en el título."

Además, en el párrafo $k$ ) indica esta norma referente a los bienes de naturaleza urbana y rústica. k) "En el caso de siniestro y otra causa que origine la pérdida total o parcial de los elementos a que se refieren las letras $a$ (urbana) y $b$ (rústica) de este apartado, el valor de las mismas se reducirá en el importe del deterioro sufrido."

Según vemos, la titularidad de los bienes urbanos puede encontrarse en distintas situaciones, tales son: 
a) Valor actualizado. Si los bienes urbanos se actualizaron en la declaración de 1978, en general se declararán por el mismo valor actualizado en 1978, siempre que el valor actualizado sea mayor que el resultante de aplicar la norma general de valoración que indique la ley de computación por su valor catastral. Si fuera menor se utilizará para la valoración el valor ca tastral.

b) Bienes con valoración catastral:

En caso de que los bienes a declarar ya tenga fijado el valor catastral deberá examinarse ese recibo y determinar si la Renta Catastral es mayor, igual o inferior al $4 \%$ del valor catastral.

- Si la Renta Catastral es mayor o igual que el $4 \%$ del valor catastral, se consignará en la declaración este último.

- Si la Renta Catastral es inferior al $4 \%$ del valor catastral, el valor a consignar es la Renta Catastral capitalizada al $4 \%$, lo que equivale a multiplicarla por 25 .

c) Bienes pendientes de valoración catastral:

Se declararán por su coste de adquisición, rectificándose este valor en cuanto se conozca el Valor Catastral.

En el caso de que el bien en cuestión se hubiera adquirido después de julio de 1980, se declarará el valor comprobado en el Impuesto sobre Transmisiones Patrimoniales.

d) Bienes urbanos en construcción:

Se declarará el valor del solar según la norma general de valoración de los bienes de naturaleza urbana, y en caso de que no se conozca el valor catastral se valorará por su coste de adquisición, con la salvedad antes apuntada de bienes comprados después de julio de 1980, más el importe de todas las cantidades efectivamente empleadas en la construcción del bien.

Recordemos que los bienes urbanos declarados monumentos históricoartísticos están exentos del Impuesto. Deben declararse, pero no debe consignarse por ellos valoración alguna.

b) Bienes de naturaleza rústica.

La valoración de estos bienes se regula en el art. sexto, apartado 6 de la ley y en el art. 11 b) y k) de la O. M. de 14 de enero de 1978.

Debemos tener en cuenta, antes de efectuar cualquier valoración de estos bienes, que al valorar una finca se entienden incluidos en el valor todos los bienes que usan para su explotación, como maquinaria, abonos, piensos, silos y construcciones similares.

Las distintas situaciones en que se pueden encontrar estos bienes a efecto de su valoración por este Impuesto son:

a) Que se hubiera procedido a la actualización de valores en 1978, en 
cuyo caso se declarará este valor salvo que fuera inferior al valor catastral de la finca.

b)Valoración de las explotaciones agrarias.

La regla general de valoración de estos bienes es la de capitalizar al $4 \%$ (multiplicar por 25) la base imponible de la Cuota Fija de la Contribución de Rústica y Pecuaria.

La ley considera grandes explotaciones a las que tienen un valor a declarar superior a 7.500 .000 pesetas, sin incluir la ganadería independiente, y que pertenezcan a un mismo propietario. Nótese que no se acumula el valor de las explotaciones agrarias de los miembros de la unidad familiar, sino solamente las de cada miembro independientemente de los demás.

Cuando el valor de todas las fincas de un mismo propietario supera el valor que hemos dicho, el exceso se multiplica por tres, y este producto, sumado a los 7.500.000, es el valor a incluir a efectos de este impuesto.

A efectos de la aplicación de la norma, es de notar que las fincas pertenecientes a una sociedad de gananciales no se consideran pertenecientes a un mismo propietario, sino a dos, al marido y a la mujer.

c) Ganadería independiente

Por ganaderfa independiente se entiende a efectos fiscales el conjunto de cabezas de ganado que esté comprendido en alguno de estos casos:

1.-Que paste en tierras no explotadas por el dueño del ganado.

2.-Que esté estabulado fuera de las fincas rústicas.

3.-El transhumante.

4.-El que se alimente fundamentalmente con piensos no producidos en la finca en que se críe.

Se valorarán aplicando la regla general de valoración (capitalización al $4 \%$ de la base Imponible de la Cuota Fija de la Contribución Rústica y Pecuaria), con la salvedad de que si se trata de ganado de reproducción, cuyo ciclo pueda repetirse en el año, sólo se declarará la mitad del valor obtenido, según la norma anteriormente indicada.

d) Fincas situadas en zonas declaradas catastróficas.

En estos casos se declara el bien pero sin valorarlo.

Esta situación se refiere al momento del devengo. Es entonces cuando la finca debe estar en zona catastrófica.

c) Bienes afectos a actividades empresariales.

El conjunto de los bienes afectos a estas actividades, no se valoran según las normas generales del impuesto, sino que se valoran por su valor neto $y$ conjunto que resulte de la contabilidad llevada con arreglo al Código de Comercio.

De acuerdo con lo anterior, no se valorará cada bien independiente- 
mente, sino el neto patrimonial de la actividad empresarial, que resulte de la aplicación de las normas contables de general aceptación, de acuerdo con los requisitos del Código de Comercio.

Como es lógico, esta rúbrica sólo tiene sentido en caso de empresas individuales, pues en caso de empresas con forma de sociedad, la parte correspondiente del capital de la sociedad que tuviera el sujeto pasivo se incluiría en el apartado de "títulos de renta fija y variable".

Cuando no se lleve una contabilidad con arreglo a las normas anteriormente citadas, habrá que declarar todos los bienes afectos individualmente, como si no estuvieran afectos a una actividad empresarial, lo que constituye una penalización a la no llevanza de contabilidad, toda vez que es sabido que las contabilidades reflejan valores históricos y la mayor parte de los activos empresariales (equipos, maquinaria, etc.) al no tener norma específica de valoración, se valorarían al valor de mercado en la fecha de devengo del Impuesto, en caso de que, a causa de inexistencia de contabilidad, hubiera que valorarlos independientemente unos de otros.

\section{d) Depósitos bancarios.}

Es de tener en cuenta que no se consideran los depósitos por cuenta de terceros, y en el caso de Libretas de Ahorro, Cuentas Corrientes o Plazos Fijos con varios títulares, a efectos de su imputación habrá que atenerse a los pactos entre partícipes, $y$ caso de que no existan o no se puedan probar, se dividirá el saldo en tantas partes como titulares.

Como excepción a la norma general, no se declara, según la ley, el saldo a 31 de diciembre sino el saldo medio anual ponderado con los días que están impuestos.

Este saldo medio ponderado debe corregirse:

a) En caso de compra de bienes con cargo a estas cuentas. Para evitar considerar duplicados el valor del bien - una vez por el propio bien y otra por el saldo de la cuenta - se resta del saldo de la cuenta, desde el 1 de enero hasta que se retiraron los fondos el valor o la parte del valor del bien que se pagó con dichos fondos.

b) En caso de cancelación de deudas y con la misma justificación que en el caso anterior, también procederá la corrección por el mismo sistema.

c) En cuanto a las deudas que existan en 31 de diciembre hay que distinguir:

- Deudas basadas en préstamos obtenidos durante el año e ingresado en c./c. o libreta de ahorro. En este caso la deuda deja de computarse en el saldo de la cuenta desde la fecha de su ingreso hasta el 31 de diciembre, y tampoco se computa en el apartado deudas. 
- Deudas provenientes de ejercicios anteriores o que, obtenidas en éste, no hayan sido ingresadas en $\mathrm{c}$./c.

En este caso, la Ley 50/77 art. 6 apartado k) indica: "Los saldos acreedores al 31 de diciembre de las cuentas corrientes y otros depósitos bancarios se aplicarán a las deudas y el resto, en su caso, se valorará por su saldo medio."

Observamos que si esto se realizara obtendriamos ya un Patrimonio Neto, pues ya habramos descontado las deudas; por tanto, este Patrimonio no serviría para calcular el ajuar doméstico, ya que éste se calcula mediante la aplicación de un porcentaje sobre el Patrimonio bruto.

A causa de esto, es un criterio ya general, pese al art. $6 \mathrm{k}$ de la Ley $50 / 77$, no tener en cuenta estas deudas a efectos de la valoración de los depósitos bancarios, teniéndose en cuenta, en cambio, en el apartado deudas minorando el Patrimonio Bruto en el que ya estaría comprendido el ajuar doméstico.

Pese a lo dicho anteriormente y para saldo de pequeña cuantía, con el fin de evitar estos cálculos engorrosos, existe la posibilidad de utilizar el saldo final al 31 de diciembre, no legalmente, pero si utilizando una consulta no vinculante al año 1977 que permitía esto.

En caso de utilizar el saldo final, no procedería efectuar en el mismo ninguna corrección.

e) Certificados de depósito.

Se valoran por su nominal.

Hay dos cautelas legales: $1 .^{\text {a) }}$ se imputará la persona en cuyo nombre aparezcan en el registro del banco emisor, salvo que se pruebe que se transmitieron a otra persona. 2. ${ }^{\text {a) }}$ los Bancos deben anotar el titular inicial y los sucesivos titulares por transmisiones.

f) Seguros de vida.

Se valoran por su valor de rescate en la fecha de devengo del impuesto, es decir, en 31 de diciembre.

g) Títulos de renta fija y variable.

En caso de poseer este tipo de bienes, pueden darse las siguientes circunstancias:

a) Títulos de renta variable cotizados en bolsa. Se valoran según la cotización media del último trimestre anterior al trimestre del impuesto.

b) Títulos de renta variable no cotizados en bolsa. Se computan por el 
valor teórico que resulte del último balance aprobado.

c) Títulos de renta fija. Si cotizan en bolsa, se valoran según la cotización media del último trimestre del año. Si no cotiza en bolsa, se valoran por el nominal.

d) Cualquier otra obligación, beneficio o derecho de crédito por deuda pública o privada se valorará por su nominal.

h) Derechos reales de disfrute.

Se valorarán de acuerdo con las normas del Impuesto sobre Transmisiones Patrimoniales y Actos Jurídicos Documentados que dice:

- En caso de usufructo temporal se multiplica por 2 el número de años de duración del usufructo, y éste es el porcentaje que del valor del bien corresponde al usufructuario. El porcentaje nunca podrá ser mayor que el $70 \%$ del valor del bien.

- En caso de usufructo vitalicio se resta de 90 los años que tenga el usufructuario, y éste es el porcentaje que le corresponde. Este porcentaje no puede ser inferior al $10 \%$ ni superior al $90 \%$.

- En caso de derecho de uso o habitación, se aplican las normas anteriores, pero referidas al $75 \%$ del valor total del bien.

i) Ajuar doméstico.

Se puede decir que el ajuar doméstico está constituido por:

- Efectos personales.

- Utensilios domésticos.

- Bienes, muebles de uso particular del sujeto pasivo, joyas, obras de arte, automóviles y embarcaciones cuyo valor unitario no exceda de 250.000 pesetas.

Hay que hacer constar lo siguiente:

- No se incluyen en el ajuar las colecciones de sellos y monedas por lo que se valoran a precio de mercado.

- Las obras de arte incluidas son las no exentas.

- En caso de bienes pertenecientes, según la descripción anterior, al ajuar con valor unitario superior a 250.000 pesetas se excluye el exceso de esta cantidad.

La norma de su valoración se recoge en el art. 6, apartado h) que indica:

El ajuar doméstico se estimará en los siguientes valores respecto del resto del Patrimonio: 
- El tres por ciento de la parte del Patrimonio con valores comprendidos entre cero y veinte millones de pesetas.

- El cinco por ciento en lo que exceda de veinte millones de pesetas.

Se incluirán en ambos casos dentro del ajuar las joyas, obras de arte, automóviles o embarcaciones, en cuanto su valor unitario no exceda de doscientas cincuenta mil pesetas.

-Otros bienes y derechos.

Se valoran por su precio de mercado en la fecha de devengo del impuesto.

Dada la dificultad de determinar su valor, hay que tener en cuenta la posibilidad de la Administración de realizar una tasación pericial contradictoria, en caso de no estar de acuerdo con dichas valoraciones.

-Deudas.

Se valoran por su nominal. No se incluyen los intereses. Hay que cuidar de no confundirlas con las cargas reales. La hipoteca sobre un bien inmueble se considera deuda y no carga, si garantiza el precio aplazado en la compra del inmueble.

Es preciso justificarlas para poder deducirlas. Los contribuyentes por obligación real sólo podrán deducir las deudas que afecten a los bienes o derechos situados, o que puedan ejercerse en territorio español.

No se pueden deducir como deudas las cantidades avaladas, en tanto en cuanto no esté obligado el avalista al pago de la deuda por falta de pago del deudor.

-Base imponible.

La constituyen la suma del valor de los bienes y derechos numerados en el importe de las deudas.

Un esquema del cálculo de la base imponible serfa el siguiente: 
URBANA

RUSTICA

B. AFECTOS A NEGOCIO

DEPOSITOS BANCARIOS

CERTIFICADOS DE DEPOSITO

SEGUROS DE VIDA

TITULOS DE RENTA FIJA Y VAR.

OTROS BIENES

$$
3 \% 65 \%
$$

AJUAR DOMESTICO

DEUDAS
PATRIMONIO BRUTO

DEUDAS

BASE IMPONIBLE

-La base liquidable.

Resulta de restar a la base imponible las reducciones de mínimo exento $y$ familiares.

Las reducciones establecidas en la ley son:

1.-Mínimo exento: 4.000 .000 pesetas.

2.-Matrimonio: 2.000 .000 pesetas.

3.-Por cada hijo menor con deudas a desgravación en el IRPF: 500.000 pesetas.

4. - Por cada hijo invidente, gran mutilado o gran inválido con derecho a desgravación en el IRPF: 1.000 .000 pesetas.

La Ley de Presupuestos Generales del Estado para 1980 modificó estas deducciones estableciéndolas en:

1. -6.000 .000 pesetas.

2. -3.000 .000 pesetas.

3. - 750.000 pesetas.

4. -1.500 .000 pesetas.

Estas últimas son las aplicables en la declaración correspondiente al año 1983.

- La cuota tributaria.

Resulta de aplicar el tipo de gravamen a la base liquidable, dentro del 
límite máximo establecido.

El tipo de gravamen es una escala progresiva por escalones. Esta escala es:

Porción de base liquidable comprendida entre:

$\begin{array}{ll}0 \text { y } 25 \text { millones: } & 0,20 \% \\ \text { 25 y } 50 \text { millones: } & 0,30 \% \\ \text { 50 y } 100 \text { millones: } & 0,45 \% \\ 100 \text { y } 250 \text { millones: } & 0,65 \% \\ \text { 250 y } 500 \text { millones: } & 0,85 \% \\ 500 \text { y } 1.000 \text { millones: } & 1,35 \% \\ 1.000 \text { y } 1.500 \text { millones: } & 1,35 \% \\ 1.500 \text { y } 2.500 \text { millones: } & 1,70 \% \\ \text { Más de } 2.500 \text { millones: } & 2 \%\end{array}$

\section{-El limite máximo.}

Para respetar el mandato Constitucional de que los impuestos no tengan alcance confiscatorio, o sea, que el impuesto sobre el Patrimonio debe ser pagado con la renta obtenida por los bienes y no con el producto obtenido por la venta de éstos, por lo que se establece un límite, estimado en porcentaje sobre la Base Imponible del Impuesto sobre la Renta de las Personas Físicas, de las cuotas íntegras conjuntas de este impuesto y el Impuesto Extraordinario sobre el Patrimonio.

Este límite, que fue establecido por el Reglamento del IRPF, en su art. 116 , en el 55 por 100 , ha sido elevado por la ley $9 / 80$ de 13 de julio de Presupuestos Generales del Estado para 1983 hasta el 65 por 100.

Si ocurre que las cuotas integras de ambos impuestos superan el porcentaje establecido, se deberá reducir la cuota integra del Impuesto sobre el Patrimonio hasta alcanzar este límite.

Para hacer este cálculo hay que tener en cuenta que no se considera la parte de cuota que corresponda a bienes no suceptibles de producir renta, pues para estos bienes no hay límite.

\section{-Deducciones por doble imposición.}

Se deducirá de la cuota integra la menor de estas dos cantidades:

La cantidad pagada en el extranjero por impuesto de la misma naturaleza, o el resultado de aplicar el tipo medio efectivo del impuesto a la parte de base liquidable gravada en el extranjero.

Esta deducción trata de evitar que por la tenencia de un mismo bien un contribuyente se vea gravado dos veces, en el caso de que tribute en España por obligación personal, por el hecho de tener bienes en el extranjero (donde tributa por obligación real). 
-Deducción por Ceuta y Melilla.

Se estableció por la O. M. de 9 de mayo de 1978. Se gira sobre la cuota integra por la parte de cuota que corresponde a bienes o derechos que radican o sean exigibles en Ceuta y Melilla. Es el $50 \%$.

Vista ya una panorámica del Impuesto, vamos a resolver un supuesto práctico referido a 1 año, 1983, que sirva para ilustrar lo expuesto.

\title{
Supuesto
}

Enunciado:

Doña Paquita Cerezo, de 31 años, que a pesar de sus intentos sigue soltera, habiendo conocido en la discoteca "Zodiaco" a don Alfonso Recámez, del que ella desconoce su condición de Inspector de Hacienda, y con el avieso propósito de obnubilarle con sus "encantos", le cuenta que posee los siguientes bienes:

1.-Un piso en Guadalajara comprado en 1977 en 5 millones de pesetas, y valorado en el Impuesto sobre el Patrimonio de 1978 en 3.798 .240 pesetas, con valor catastral en 1983 de 3.000 .000 de pesetas.

2.-Un piso en Melilla que tiene alquilado a dos estudiantes, por el que recibe 300.000 pesetas anuales y que tiene un valor catastral de 750.000 pesetas (1976 año de implantación de la CTU).

3.-Además, posee un cortijo en Córdoba denominado "La Bruja" con una base imponible de la Contribución Territorial Rústica y Pecuaria de 1983 de 300.000 pesetas.

4.-Posee los siguientes depósitos bancarios o en la Caja de Ahorros de Antequera, oficina de Melilla.

\author{
CUENTA CORRIENTE \\ Saldo a 31-XII-83 \\ 1.800 .000 \\ Saldo Medio \\ 1.250 .000 \\ Saldo a 31-XII-83 \\ LIBRETA DE AHORROS \\ Saldo Medio \\ 1.325 .000

\section{PLAZO FIJO (Constituido en 1-7-83)}

\section{Saldo a 31-XII-83 \\ 1.000 .000} \\ Saldo Medio \\ 500.000 \\ 5.-Tiene 1.000 acciones de 500 pesetas nominales de la empresa "Cons- \\ trucciones Barrendero, S. A.", de la que por la calle se dice: \\ "Si le compras un piso a Barrendero, \\ te quedas sin piso y sin dinero." \\ El valor teórico de las citadas acciones, según comunicación de la ci-
}


tada sociedad es del $85 \%$, aunque el capital social más las reservas de la citada sociedad son de 3.000 .000 de pesetas, siendo el número de acciones de 4.700 .

6.-Posee dos coches:

Un "Alfalfa Romeo" valorado en 500.000 pesetas.

Un Seat 600 valorado en 25.000 pesetas.

Como doña Paquita se administra bien, no tiene deudas.

Don Alfonso, tras darse a conocer, le conmina a que declare este año por el Impuesto Extraordinario sobreel Patrimonio, tras levantarle un acta "in situ" por los dos últimos años que dona Paquita, ocupada buscando novio, no había tenido un huequecito para cumplir sus deberes fiscales.

Doña Paquita, al día siquiente, le encarga a usted le haga su declaración del año 1983 por el Impuesto sobre el Patrimonio.

\section{SOLUCION}

-URBANA.................

3.798.240

Piso Guadalajara .............

Piso Melilla

$(750.000 \times 1,08 \times 1,35) \ldots \ldots \ldots \ldots$

-RUSTICA

1.093 .500

Cortijo Córdoba

$300.000 \times 25 \ldots \ldots \ldots \ldots \ldots \ldots$

-DEPOSITOS EN C./C. . . . . . . . .

C./c.

7.500 .000

Libreta de Ahorros .............

Plazo Fijo

-PARTICIPACIONES SIN COTIZACION

EN BOLSA. . . . . . . . . . . . . . .

4.891 .740

Construcciones Barrendero

$(1.000 \times 500 \times 0,85)$

-DEMAS BIENES Y DERECHOS ......

Alfalfa Romeo.

1.250 .000

1.325 .000

500.000

7.500 .000

3.075 .000

425.000

250.000

250.000

TOTAL SUMA (1)

16.141 .740

484.252 (7)

TOTAL BIENES Y DERECHOS. . . . . . . .

16.625 .992

DEUDAS. 
BASE IMPONIBLE $\ldots \ldots \ldots \ldots \ldots \ldots$

\section{REDUCCIONES}

Tipo medio efectivo de gravamen

$$
\frac{\mathrm{CI} \cdot 100}{\mathrm{BI} \cdot}=\frac{21.252 \cdot 100}{16.625992}=0,1278239 \%
$$

Parte de Base Imponible en Melilla:......

Parte de cuota correspondiente a los bie-

nes y derechos situados en Melilla: (11)

$$
\frac{5.327 .752 \cdot 0,1278239}{100}=6.810
$$

Dedución $50 \%$ de $6.810 \ldots \ldots \ldots \ldots$

CUOTA LIQUIDA ............

\section{I. Cuota integra}

B. I. Base imponible

\section{NOTAS}

(1) Para los bienes comprados con anterioridad a 1978 se considera valor adquisición el valor declarado en el Impuesto Extraordinario sobre el Patrimonio de las Personas Físicas del año 1978, siempre que sea superior al que resultaría aplicando la regla de capitalización del Impuesto sobre el Patrimonio. Norma: Ver disposición transitoria $2 .^{a}$ del Reglamento del I.R. P. F.

(2) Dado que es en 1976 el año de implantación de la Contribución Territorial Úrbana, hay que actualizar el valor catastral por el coeficiente recogido en el art. $60^{\circ}$ de la ley $50 / 77$, que es el 1,08 y el producto resultante por el coeficiente 1,35 señalado en la ley $74 / 80$ de 29 de diclembre de Presupuestos Generales del Estado para 1981 . Norma: art. $6 .^{\circ}$ a) de la ley 50/77.

(3) La capitalización al $4 \%$ de que habla la ley da indéntico resultado que multiplicar por 25 la Base Imponible de la Contribución Territorial Rústica y Pecuaria. Norma: art. 6. ${ }^{\circ}$ b) de la ley 50/77. 
(4) No obstante, existe una consulta no vinculante en el sentido de que podrian utilizarse los saldos finales del ejercicio, pero entendemos que lo dicho en esa consulta tiene como finalidad evitar lo engorroso de los cálculos correctores de los saldos medios en caso de compra de bienes o de cancelación de deudas. Como en este supuesto no se da lo mismo de los dos casos, y además los saldos no son de pequeña cuantía, entendemos como más correcto la aplicación del criterio de valoración de la loy. Norma: art. 6 ; d) de la ley 50/77.

(5) Con arreglo a la norma legal la valoración de estas participaciones ha de hacerse a valor teórico, resultante del último balance aprobado. Norma: art. $6 \mathrm{f}$ ) párrafo $1.0^{\circ} \mathrm{de}$ la ley 50/77.

(6) El art. $6 .^{\circ} \mathrm{h}$ ) párrafo $4 .^{\circ}$ de la ley $50 / 77$ indica:

"Se incluirán en ambos casos o dentro del ajuar las joyas, obras de arte, automóviles o embarcaciones, en cuanto su valor unitario no exceda de 250.000 pesetas."

A "Sensu contrario" de este precepto, parece que en cuanto el valor unitario de las joyas, obras de arte, automóviles o embarcaciones superará las 250.000 pesetas no deberían incluirse en el ajuar, sino en otros bienes y derechos por su totalidad.

Sin embargo, la O. M. de 14 de enero de 1978 determina que se excluye del ajuar no el total, sino sólo el exceso de las 250.000 pesetas.

Pese a la objeción expuesta, en la resolución del supuesto hacemos caso de la norma reglamentaria.

(7) Norma: art. $6 \mathrm{~h}$ ) de la ley 50/77.

(8) E1 art. $70^{\circ}$ de la ley $50 / 77$ indica las reducciones en concepto de mínimo exento, que es el caso a aplicar, ya que doña Paquita no está casada ni tiene hijos, de 4.000 .000 pesetas.

Sin embargo, esta reducción fue elevada a 6.000 .000 pesetas por el art. trigésimo de la ley $42 / 77$ de Presupuestos Generales del Estado para 1980.

(9) Norma: art. 9. ${ }^{\circ}$ de la ley $50 / 77$.

(10) Se ha utilizado el mismo procedimiento de cáculo que se desprende la ley para el caso de deducción por doble imposición internacional.

Es de notar que el impreso del Impuesto al calcular el tipo medio de gravamen no utiliza en el denominador la base imponible, sino la liquidable, quizá a causa de una interpretación de la O. M. 14-1-78, lo que es preciso tener en cuenta al liquidar el impuesto en su impreso oficial.

(11) Los bienes y derechos que se consideran situados en Melilla son:

- El piso situado en ésta plaza . . . . . . . . . . . . . . . 1.093 .500

- Los depósitos en cta.jcte. . . . . . . . . . . . . . . . . $\quad 3.075 .000$

- Acciones construcciones Barrendero, S. A. . . . . . . . . . . 425.000

- Demás bienes y derechos . . . . . . . . . . . . . . 250.000

- Ajuar. . . . . . . . . . . . . . . . . . . 484.252

(Si reside en Melilla, su ajuar doméstico debe estar aqui)

5.327.752 Pts.

\section{BIBLIOGRAFIA}

BRENA CRUZ, Fernando A.: Impuesto Extraordinario sobre el Patrimonio de las Personas Fisicas. Ed. Ministerio de Hacienda. Servicio de Publicaciones. Colección: Legislación Tributaria Comentada. Madrid, 1982.

BANAClOCHE PEREZ, Jullo; GONZALEZ GARCIA, Angel Luis; SARMIENTo CASTAÑon, Rufino: El Impuesto extraondinario sobre el Patrimonto. Ed. Banco Hispano Americano. Madrid, 1981.

Varios: Curso de Tributación. Ed. Instituto de Estudios Financieros. Madrid. 1981.

Varios: Compendio de Derecho Tributario Español. Manuales de la Escuela de Inspección Financiera y Tributaria. Madrid, 1979. 